\title{
SUSTAINABILITY IN THE AGE OF DISRUPTION
}

KEYWORD: disruptions, social institutions, sustainable development, improvement, digital

\section{Dr.k.narendra Kumar*}

\section{P.kalpana}

\section{Dr.p.sridhar Rao}

Associate Professor,Department of Management Studies,Vishnu Institute of Technology, Bhimavaram. *Corresponding Author

Assistant Professor,Department of Management Studies,Vishnu Institute of Technology, Bhimavaram.

Professor \& Head, Department of Management Studies,Vishnu Institute of Technology, Bhimavaram.

Social institutions and disruptions to technology will force significant changes to the indigenous habit and intergenerational value that we can't be neglected. Sustainable development research has moved from the edges to the standard of the executives thinks about. As business exercises break planetary limits, Sustainable development is more basic and dire than any other time in recent memory. However, the world has not stopped as the more extensive field of the executives studies mulls over the significance of reasonable improvement. Real propels in digital advancements and the disintegration of social foundations has made an ideal tempest, with the goal that sustainable development might be a considerably progressively slippery perfect.

INTRODUCTION:

\section{DISRUPTION}

Disruption has started to seem like nothing more than someone having a great idea. The original theory actually points to a specific process through which a business disrupts others, taking their market share by targeting overlooked customer segments. The disruptive business then moves into the mainstream, gaining more and more market share while also staying agile and able to outmaneuver the competition. An authentic disruption definition must work in any industry, for any business model and for any brand.

\section{How To Spot Disruption In Business}

They Aren't Always Flash: One problem with identifying disruptors is that often they need lots of time to make a real impact in their respective fields. Sometimes it can take years for the true effects of disruption to present itself in the market. Additionally, a disruptor's business model can look completely different than what's already there, so it can be hard to identify disruptive innovation in early stages. This is especially true of companies that anticipate social shifts that few others in the industry are aware of.

They Add Real Value: Most true disruptors aren't setting out just to be disruptors. Like any other business owner, they want to provide a product or service that adds real value for their customers. The best disruptors are those who are innovating constantly because they find meaning in their mission. Their business is revealed as disruptive only over time as they make their mark, often permanently changing an entire industry. They never really focus on the question "What is the meaning of disruption?" because they don't care. Their priority is making a difference.

They do things differently: It's easy for other businesses in a market to write off potential disruption. A disruptive business doesn't appear to be a threat at first because their ideas are so out there that others expect them to fail. Or it may follow an uncommon business model, like Apple's iPhone, which directly connected developers with users in new-fangled things called "apps" - and changed the communications industry forever.

\section{How To Build A Disruptive Innovation Strategy}

Creating a disruptive innovation strategy requires an actionable plan for getting from where you are now to where you want to be. It puts your desire for disruption into motion.
Having a strategy allows you to anticipate disruptive forces coming into your industry so you can plan for - and benefit from them.

\section{DETERMINEYOUR X FACTOR}

The phrase "disrupt or be disrupted" is a misnomer. In many ways, debating whether or not Tesla Motors or Apple fits the disruptive model or not misses the point. What matters more is turning your customers into lifelong devotees, not making this or that product disruptive.

It's about finding new and better ways to engage and retain your customers, such as with Artificial Intelligence (AI). Depending on how it's used, AI might not qualify as business disruption because it's been heavily utilized for decades. But whether it's disruptive or not, it can provide an easy and effective way to connect with your customers and can make your business more successful. By anticipating the changing needs of customers, innovation and disruption will occur naturally. When you take the focus off of disruption and put it on solving problems for customers, It will always head in the right direction.

\section{PRACTICE CANI}

Another way to think about success via innovation comes from Tony's Business Mastery event. As Tony says, Innovation, what is innovation? It's not tech. Innovation is any way you find a way to do more for a client than anybody else does.

Unless constantly innovating, and innovating in a way that customers care about, Its going to be in the dust. That's CANI -constant and never-ending improvement.

If an entrepreneur and back that up with action in business, will seek out innovation and improvement at every turn. Business will not settle for the status quo when you know that your business can do more. Conversely, a proprietor is happy to put in hours, make a modest profit and never disrupt the status quo. In short, a proprietor maintains the status quo. An entrepreneur has a growth mindset and is a natural born disruptor.

\section{Stay In Touch With The Market}

Disruptive innovation requires keeping in touch with technological advances in your industry so to stay one step ahead. To disrupt instead of being disrupted, so keep a pulse on competition. 
"Disruptive innovation is a high stakes game, with high risk and potentially high rewards," explains Alison Coleman in Forbes. "It's also very difficult to spot the winning disruptive opportunities, especially when disruptive ideas require other players in the ecosystem to acknowledge and embrace the change."

Don't be afraid to disrupt own brand. Self-disruption constantly adapting product to remain relevant - can only help. Forbes reports on Apple's use of disruption as a longterm growth strategy. The company's iPod revenue dropped by $\$ 345$ million because of Apple's own disruptive innovation: the iPhone, which generated $\$ 18$ billion in revenue.

\section{OPTIMIZE FROIMWITHIN}

Don't get tricked into thinking that because business isn't on the scale of Netflix, there are no lessons to be learned. Businesses of any size can engage in disruption. But to do so, must work from within the own company.

Before growing business, must optimize company from within.This is where we can turn to business guru Jay Abraham. He argues that many business owners want growth, but their focus is trained outside of their business. This is a mistake. To successfully prepare your business for real growth, disrupt business from within by analyzing existing structure. Instead of engaging in disruptive innovation blindly, Jay Abraham advocates for careful examination of your business from the inside out.

\section{SCALE MINDFULLY}

Once have a handle on what business really in, begin the process known as mindful scaling. Start with sales force. Before invest in a new software system to automate team's numbers, look first at their processes.

Don't stop at analyzing sales team. Take a look at marketing strategy as well. If numbers are flat, it's time to experiment with new avenues of messaging. While you're at it, take a look at how to serve existing customers. Are meeting their needs? Are there ways can serve them faster and make their process easier and more streamlined?

Remember, a hallmark of disruptive innovation is the ability to play the long game as well as maintain your initial advantages even as you take more market share. This requires a comprehensive business map, a powerful vision for your organization and excellent goal-setting and decision-making skills. All of these things will help you scale mindfully and become a successful example of disruption rather than a forgotten failure.

\section{DON'T FORCE DISRUPTION}

No one can deny the popularity of business disruption and what the term implies. Most entrepreneurs are naturally innovative, and most innovators have dreams of changing the world. This is one of the reasons why disruption is so appealing.

Because disruptive innovation has become synonymous with progress - and everyone likes progress - many companies attempt to style themselves as "disruptive" right from the getgo. But here's the secret: not every successful business or product needs to disrupt.

Take virtual reality. New innovations have led to the creation of a new market poised to change how we experience everything from sports to education.

\section{SUSTAINABILITY}

Sustainability has picked up as much significance as the board in business. Sustainable pavement improvement as a business practice ought to include making assessments as per the triple primary concern in the asphalt life-cycle.
Sustainability focuses on meeting the needs of the present without compromising the ability of future generations to meet their needs. The concept of sustainability is composed of three pillars: economic, environmental, and social-also known informally as profits, planet, and people. Sustainability encourages businesses to frame decisions in terms of environmental, social, and human impact for the long-term, rather than on short-term gains such as next quarter's earnings report. It influences them to consider more factors than simply the immediate profit or loss involved. Increasingly, companies have issued sustainability goals such as commitment to zero-waste packaging by a certain year, or to reduce overall emissions by a certain percentage. These companies can achieve their sustainable needs by cutting emissions, lowering their energy usage, sourcing products from fair-trade organizations, and ensuring their physical waste is disposed of properly and with as small of a carbon footprint as possible.

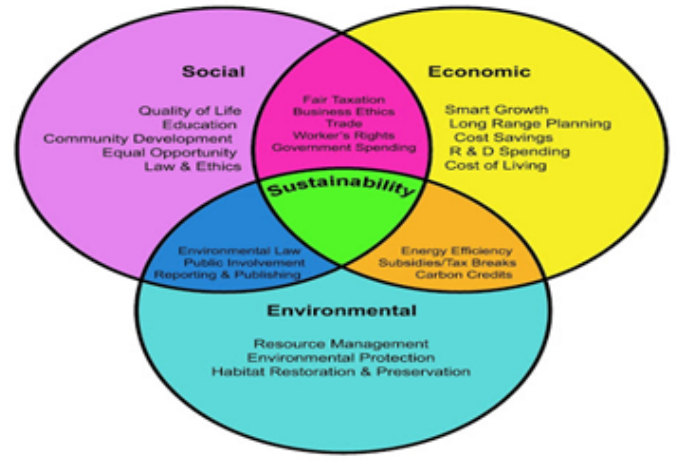

\section{DIGITAL DISRUPTION}

Digital disruption is the change that occurs when new digital technologies and business models affect the value proposition of existing goods and services. The rapid increase in the use of mobile devices for personal use and work, a shift sometimes referred to as the consumerization of IT, has increased the potential for digital disruption across many industries.

Generally, digital disruption happens after a digital innovation, such as big data, machine learning (ML), internet of things (IoT) or the bring your own device (BYOD) movement. Digital innovation then affects how customer expectations and behaviors evolve, causing organizations to shift how they create products and services, produce marketing material and evaluate feedback. This shift in digital strategy can occur on an individual, organizational, industry or societal level.

The term digital disruption has become something of a cliché in recent years and is often misused to describe any product involving digital technology or the use of digitization to better compete against marketplace peers. It is often confused with the term disruptive technology, a term coined by Harvard Business School professor Clayton M. Christensen to describe a new technology that displaces an established technology.

\section{Importance Of Digital Disruption}

It is important for organizations to embrace digital disruption in order to gain a competitive advantage. When an industry experiences digital disruption, it typically signals that consumer needs are shifting. Therefore, understanding the disruption allows companies to keep existing customers happy as well as create opportunities for new customers. It also gives companies a better idea of human behavior and how trends may occur over time. A few best practices to follow that ensure digital disruptions are more of an opportunity than a threat are:

- Pursue initiatives that might cause a disruption, do not be 
afraid to be the disruptor.

- Consolidate data assets and use them to make decisions.

- Brainstorm ideas for entirely unique products, services or channels.

- Employ customer data in new, innovative ways.

\section{Examples Of Digital Disruption}

A few examples of digital disruption include:

- The digital camera business disrupted the industry of film photography and photo processing.

- The subscription economy business model, as used by companies like Amazon, Hulu and Netflix, caused a disruption within the media and entertainment industries by changing how content is accessed by customers and monetized by advertisers.

- Freemium

- products, such as Spotify, LinkedIn or Dropbox, that allow users to sample a basic product with the option to pay for the full offer, put more emphasis on developing a wellknown brand behind a product or service.

- On-demand services, like Uber, have disrupted more traditional services like taxis.

- The rise of electronic reading has redefined the print and publication industry.

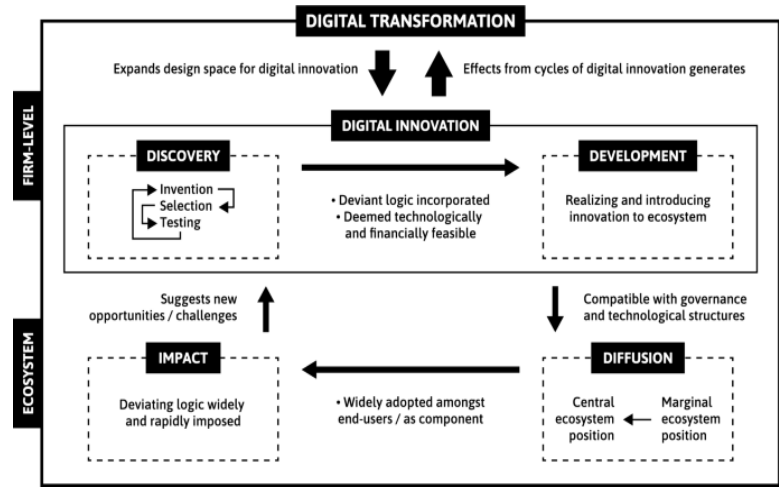

Seven Dynamic Areas That "present Rich Opportunities To Develop Radically More Sustainable Behaviour And Practice.

\section{Mobility}

Innovations for connected, autonomous, shared and electric vehicles will all bring big changes in road safety, urban planning, community interaction and the exchange of goods. Shared cars reduce traffic and improve parking, while infrastructure, regulation and grid and battery innovations are making electric vehicle production take off. Drivers will lose jobs, while technology skills will be in demand. In terms of sustainability, we should see much safer and cleaner mobility. Predominance of electric vehicles may come sooner than we thought: gas stations and electricity grids are enabling charging stations, cost-effective electric trucks are being introduced, and automakers are announcing plans to end production of diesel engines and invest heavily in electriccars.

\section{2:agriculture}

Regenerative agriculture, combined with appropriate use of automation, can have dramatic effects on the quantity and nutritional quality of our food, as well as on $\mathrm{CO} 2$ emissions. Regenerative techniques include carbon sequestration in the soil, cultivating different crops together, keeping plant cover on soil and using insects instead of chemical pesticides. The report says, "The internet of things, remote sensing, artificial intelligence and a revolution in robotics are coming together to make low-input, data-driven automated agriculture at scale a real possibility." Forum for the Future also predicts a shift from meat eating to plant-based diets. This would disrupt agriculture and livestock, and dramatically improve the environmental impacts of our diets.

|www.worldwidejournals.com
3.Retail

Clearly old ways of shopping are being disrupted, with online shopping going mainstream, a concentration of platforms (such as Amazon and Alibaba), innovation in delivery (such as the use of drones, or refrigerators that stock themselves), and greater efficiency through quick price comparison, reviews, and targeted marketing. Forum for the Future asks, "Can this be harnessed for sustainability?" Millennials are driving the sharing economy and are in many cases more interested in access than ownership. Rather than wanting to own a car, they'll access one when they need it, and they are happy to rent and share clothing, experiences, and accommodations. In her 2014 Ted Talk on collaborative consumption, Rachel Botsman said, "We are moving from passive consumers to creators, to highly enabled collaborators," and "from a cultureof 'me' to a culture of 'we'."'

\section{New livelihoods}

The Forum for the Future report expresses major concern for livelihoods in developing countries, as automation in manufacturing and agriculture replaces jobs. As in the developed world, people in developing nations will need to train in new skills for new livelihoods. Demographics won't help; the report cites a UN prediction that the global population will reach 11.2 billion in 2100 , with more than half the world's children living in Africa. The report highlights two examples of solutions: collaborative work platforms that assign tasks to the best workers anywhere in the world, and unconditional basic income (UBI). Early results of pilot UBI projects in India and Kenya are showing increased entrepreneurship.

\section{Blockchain}

Blockchain technology holds promise for more transparent tracking and decentralized innovation. The report gives examples in supply chain management, in accelerating renewable energy integration into the grid, in improving meal delivery to schoolchildren, and in a payment system for refugees. If blockchain leads to a future of self-organizing networks, for instance of small producers all contributing energy to a local grid, it could disrupt our centralized systems ofgovernance.

\section{Going Local}

Globalization is becoming less popular, with localism, protectionism and regional political identity on the rise. On a less divisive and more positive note, new trends include community energy cooperatives, local food systems, local currencies, locally-made beer, local festivals and community business. Forum for the Future points out that cities are tackling climate change with local solutions, networked together in groups such as C40 Cities and 100 Resilient Cities. In some cases the solutions are system-wide. "Boston's climate change resilience plan focuses on tackling social inequality, acknowledging that [inequality] augments the environmental effects of climate change," the report says. All of these areas are ripe with entrepreneurial opportunities and room for technological innovation. Clearly nonlinear times call for responsible application of technology, and Forum for the Future is optimistic about the direction humanity can take. We need to step up to this level of responsibility now.

\section{CONCLUSION:}

Disruption has many dimensions either it can be technical in nature or any other form of doing things are replaced by smart ones. It is the human choice that the extent to which it can be accepted or welcomed in any domain without disrupting the existing ways totally and ensure sustainability for the future generations. It does not mean that people show reluctance to adopt change. As far the business is concerned, If you're ready to take the next step toward disruption, get to know your business identity. When you truly understand what drives your company, you're prepared to take your company 
to the next level.

\section{REFERENCES:}

1. Dr.K.Narendra Kumar, MrsP.Kalpana, "Corporate Social Responsibility And Sustainability," International Journal of Social Sciences \& Humanities (IJSSH),Volume5 Issue 9, pp:97-102 june 2019 ISSN (Online) : 2395-5996 ISSN (Print) : 2454-275X.

2. Mr.K.Murali Krishna, Dr.K.Narendra Kumar and Mr.P.Ramaswamy, "A Study on Andhra Pradesh State Financial Corporation - An Overview", GEC'S International journal of Innovation Technology and Management, Volume V, Issue I, February 2019, ISSN:2394-594X.p.p:44-48,Impact factor:2.174.

3. Rauch M, Wenzel M, Wagner HT. The digital disruption of strategic paths: an experimental study.

4. Bonnet D, Buvat $J$, Kvi S. When Digital Disruption Strikes: How Can Incumbents Respond. Capgemini Consulting: Digital Transformation Review-Strategies for the Age of Digital Disruption.(S. 78-88). Capgemini Consulting. Vom Multivariantengeschäftsmodell zur softwaregesteuerten Individualisierung im Auto. 2015; 173.

5. Garcia C, Alvarez Tabio F, Bonnet D, Buvat J. Strategies for the age of digital disruption. In:Digital transformation review. Cap Gemini Consulting, 2015.

6. Knickrehm M, Berthon B, Daugherty P. Digital disruption: the growth multiplier. Accenture Strategy, 2016. 